$$
\text { ANL/CHMIPD-87624 }
$$

\title{
CARBONS FOR BATTERY ANODES PREPARED USING INORGANIC TEMPLATES
}

\author{
R. E. Winans, K. A. Carrado, and G. Sandi \\ Chemistry Division, Argonne National Laboratory
}

Unique carbons with demonstrated utility as anodes for lithium secondary batteries have been prepared by heating hydrocarbons within an inorganic template. Disordered carbons with novel and desirable molecular porosity were synthesized by the pyrolysis of pyrene at $700{ }^{\circ} \mathrm{C}$ within a pillared clay The clay was removed by treatment with acid, leaving behind carbons with 15 to $50 \AA$ holes. These holey carbons, when converted into electrodes, allow rapid diffusion of the lithium into and out of a carbon. Favorable results have been obtained in several tests, for example, a reversible capacity of $825 \mathrm{mAh} / \mathrm{g}$ has been achieved, about four times greater than commercial batteries using convention pyrolytic carbon. This work is part of a program in fundamental battery chemistry at Argonne National Laboratory supported by the Department of Energy, Basic Energy Sciences, Chemical Sciences Program.

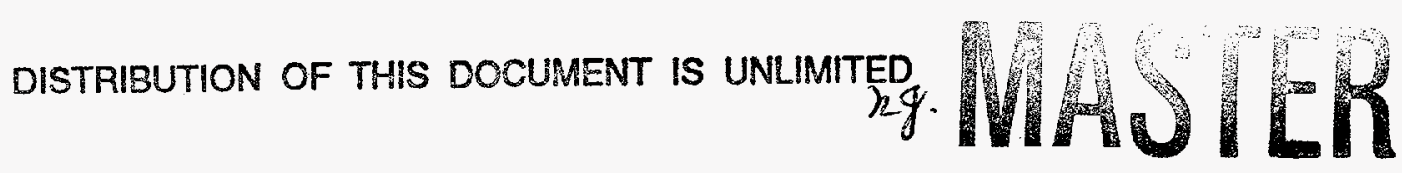

DISCLAIMER

\begin{abstract}
This report was prepared as an account of work sponsored by an agency of the United States Government. Neither the United States Government nor any agency thereof, nor any of their employees, makes any warranty, express or implied, or assumes any legal liability or responsibility for the accuracy, completeness, or usefulness of any information, apparatus, product, or process disclosed, or represents that its use would not infringe privately owned rights. Reference herein to any specific commercial product, process, or service by trade name, trademark, manufacturer, or otherwise does not necessarily constitute or imply its endorsement, recom. mendation, or favoring by the United States Government or any agency thereof. The views and opinions of authors expressed herein do not necessarily state or reflect those of the United States Government or any agency thereof.
\end{abstract}




\section{DISCLAMIIR}

Portions of this document may be illegible in electronic image products. Images are produced from the best available original document. 


\title{
Carbons for Battery Anodes Prepared Using Inorganic Templates
}

\author{
R. E. Winans, K. A. Carrado, and G. Sandí \\ Chemistry Division \\ Argonne National Laboratory
}

Unique carbons with demonstrated utility as anodes for lithium secondary batteries have been prepared by heating hydrocarbons within an inorganic template. Disordered carbons with molecular porosity were synthesized by pyrolysis at $700{ }^{\circ} \mathrm{C}$ of pyrene which has been dispersed within a pillared clay. The clay is removed by treatment with acid leaving behind carbons with particle sizes similar to the clay. Aluminum oxide pillars hold the clay layers apart and produce 15-50 $\AA$ holes in the layered carbon that is formed. These holes allow rapid diffusion of the lithium during charging and discharging. A reversible capacity of $825 \mathrm{mAh} / \mathrm{g}$ has been achieved with these carbons which is much better than the 200 $\mathrm{mAh} / \mathrm{g}$ observed with commercial batteries using what is thought to be pyrolytic carbon.

Electrode materials and their interfaces with electrolytes need to be investigated for the improvement of lithium secondary batteries. This study exploits our understanding of the limitations of the electrodes currently in use to guide the synthesis of new materials. A key element of this study is the electrode-by-design concept, which relies on unique chemical solutions for the preparation of new structured carbons. These methods, which are being exploited in other disciplines, have not yet come into use for the preparation of new electrodes. We propose to end the current dependence on empirical approaches. Currently, the most popular negative electrode is prepared from an ill-defined material called petroleum coke.

When all the elements of the problem are considered, carbon becomes the material of choice for the negative electrode of lithium rocking chair batteries. Originally lithium metal was used for the electrode, but several severe problems ended its commercial application. Consequently, the more recent work has focused on several lithium insertion compounds that maintain a lithium activity close to unity, a value that is ideally suitable for a negative electrode operating in conjunction with an iron- or manganese-oxide counter electrode. Graphite and other forms of carbon readily intercalate lithium metal. The exact composition of these $\mathrm{Li}_{\mathrm{x}} \mathrm{C}_{6}$ compounds depends on the form of the carbon; for example, for graphite and some petroleum cokes $\mathrm{x}=1.0$ at room temperature. Graphitic compounds with $\mathrm{x}>1.0$ exist only at high temperatures and pressures. An important advantage of carbon over other host insertion compounds is that the potential is very close to that of lithium metal. 
The specific capacity for the negative electrode is smaller for lithium insertion compounds than for lithium metal. However, carbon electrodes appear superior in this respect to the metal oxide alternatives that have been examined. Another important consideration is the diffusion of lithium into the electrode and its influence on the rates of charge and discharge. This matter is not well understood, and needs to be studied to define the limiting processes and provide information that can be used to guide synthetic approaches. The micro-texture and the surface area of the electrode material are also significant. These properties make petroleum coke a better electrode than graphite. Therefore, we conclude that controlling the nature of the surface of the negative electrode is a critical factor and are working toward this goal in the synthesis-by-design approach described.

A very promising carbon has been prepared by heating a pyrene-pillared clay complex at $700{ }^{\circ} \mathrm{C}$ and then removing the clay in acid solution. X-ray diffraction results suggest that the desired highly disordered carbon has been formed. The surface area of the carbon is 23 $\mathrm{m}^{2} / \mathrm{g}$, which is large and is in the range known to be appropriate for electrodes.

The LDMS spectra suggest that this material is highly carbonized. Preliminary scanning transmission microscopy (STM) and small angle neutron scattering (SANS) data strongly suggest that a layered carbon with angstrom-sized holes is produced. Low resolution STM results show carbon particles the size of the clay template and, at high resolution, the results suggest that there are holes in the carbon layers. Independently, SANS data indicate that $15 \AA$ diameter holes, which are approximately the size of the pillaring $\mathrm{Al}_{13}$ cluster, are present. Lithium should be able to diffuse rapidly through such a molecularly porous carbon.

In summary, this designed carbon synthesis, which can be more easily controlled than traditional empirical procedures, is yielding materials with desirable properties. We feel that this low-temperature carbonization is similar to the Scholl reaction, which is an acidcatalyzed condensation of aromatic hydrocarbons. 